\title{
Comment on: "Forecasting Pharmaceutical Prices for Economic Evaluations When There is No Market: A Review"
}

\author{
Przemysław Holko ${ }^{1}$ iD
}

Published online: 27 January 2017

(c) The Author(s) 2016. This article is published with open access at Springerlink.com

Dear Editor,

In their publication in Pharmacoeconomics Open, Akpinar et al. [1] reported the results of their review of methods for forecasting drug prices for economic evaluations. This was an interesting article, and I agreed with most of the conclusions. However, I disagree that prices forecast using the price of a close substitute on the same market may be more reliable. This conclusion may be biased because of market-specific aspects that were not incorporated in the study.

Akpinar et al. [1] obtained the actual (post-launch) prices from official sources in the USA or Canada. However, some of the economic analyses were conducted for different markets. The mechanisms for controlling prices differ between markets, and neglecting to account for these differences may introduce bias. Hence, the forecasting efficiency $([A-E] / E$ index proposed by Akpinar et al. [1], where $A$ is the actual and $E$ is the expected or forecast price of a drug) should be calculated using current prices in the same market for economic evaluation. The updated information for economic evaluations conducted outside of the USA and Canada $[2,3]$ are presented in Table 1. Although the general conclusions did not change (there is still no trend), the forecasting efficiency did change drastically when market-related aspects were incorporated. Additionally, there

This comment refers to the article available at doi:10.1007/s41669016-0004-1.

Przemysław Holko
p.holko@peresc.com

Pharmacoeconomic Research Center, Kraków, Poland is no advantage to the forecasting method that utilizes the price of a close substitute, i.e. the average absolute value of the $(A-E) / E$ index for a method based on a close substitute and others equalled-after correction84 and $45 \%$, respectively. Those values in the study of Akpinar et al. [1] were 68 and 80\%, respectively, indicating slightly better performance of the method using the price of a close substitute. That conclusion no longer holds true after the adjustment.

Additionally, the study touched on the conclusion that the generalizability of economic evaluations may be limited, i.e. the cost effectiveness of a drug in a specific market may not translate well to other markets, especially when the economic evaluation is based on forecast prices. Caution is always recommended when accepting a cost-effectiveness ratio based on forecast prices. Perhaps the best way to minimize the risk of misinterpreting the results of an economic evaluation and to limit the forecast price impact is to show a 'threshold price' as an endpoint (in base-case and all scenarios of sensitivity analyses). The 'threshold price' informs decision makers about the maximal price of a drug at which using it is still cost effective (e.g. associated with a cost-effectiveness ratio below the threshold [4] or less costly, depending on the type of economic evaluation). Additionally, the 'threshold price' can be presented as a function of the threshold (Fig. 1), price of a well-known drug used in the same indication across markets as a reference, or both (Fig. 2). For example, a new biological agent for the treatment of inflammatory bowel diseases (e.g. vedolizumab, ustekinumab) can use infliximab as a reference in threshold pricing presentations. Such results can be used to obtain a 'threshold price' for another market, although it is still not adjusted for all differences (e.g. medical services valuation, 
Table 1 The forecasting efficiency of pharmaceutical prices for the markets outside of the USA and Canada

\begin{tabular}{lll}
\hline & Ruconest (conestat alfa) & Prolia (denosumab) \\
\hline Study & Kawalec et al. (2013) [2] & Hiligsmann et al. (2010) [3] \\
Country (year of price forecasting) & Poland (2012) & Belgium (2009) \\
Forecast price & PLN4816.52 & EUR95.48 \\
Forecast price inflated to 2016 & PLN4825.89 & EUR106.40 \\
Actual price (source) & PLN3702.66 (http://www.mz.gov.pl) & EUR180.21 (http://www.cbip.be) \\
{$[A-E] / E$ index (origin market) $(\%)$} & -23.3 & 69.4 \\
{$[A-E] / E$ index (US/Canada market) $[1](\%)$} & 127.5 & 5.1
\end{tabular}

$A$ actual price, $E$ expected (forecast) price

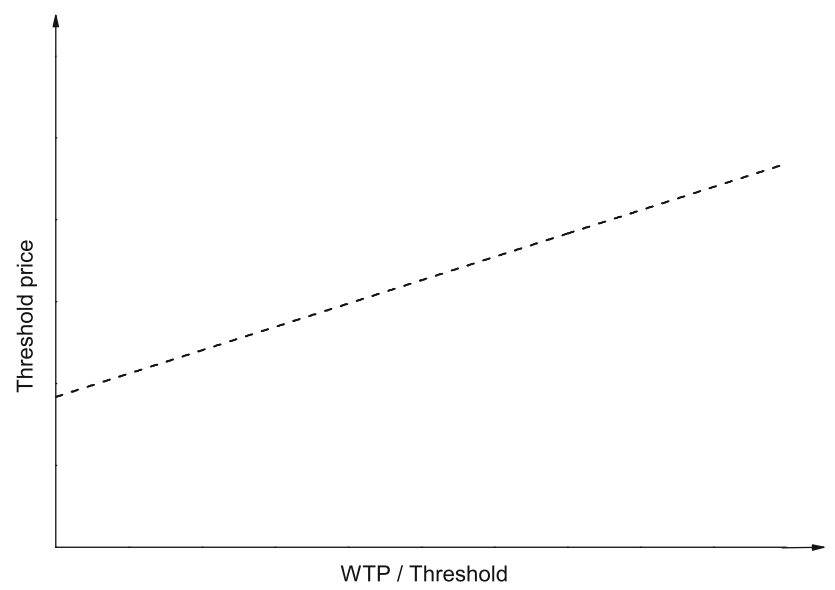

Fig. 1 Example of association between the 'threshold price' and willingness to pay for additional health effect (the threshold)

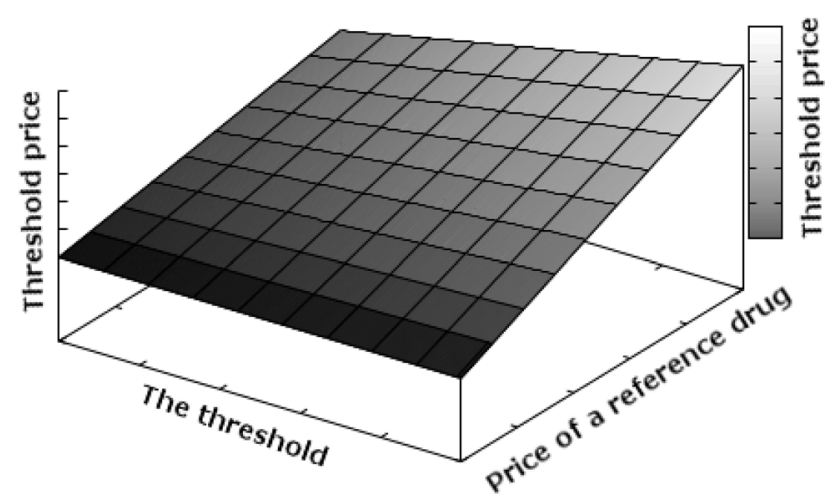

Fig. 2 Example of association between the 'threshold price', the threshold, and price of a reference drug treatment patterns). The approach can reduce the risk of misinterpretation and solve major problems in the forecasting of pharmaceutical prices for economic evaluations.

\section{Compliance with Ethical Standards}

Conflict of interest PH has no conflicts of interest.

Funding No sources of funding were used to prepare this letter.

Open Access This article is distributed under the terms of the Creative Commons Attribution-NonCommercial 4.0 International License (http://creativecommons.org/licenses/by-nc/4.0/), which permits any noncommercial use, distribution, and reproduction in any medium, provided you give appropriate credit to the original author(s) and the source, provide a link to the Creative Commons license, and indicate if changes were made.

\section{References}

1. Akpinar I, Jacobs P, Tran TD. Forecasting pharmaceutical prices for economic evaluations when there is no market: a review. PharmacoEconomics Open. 2016. doi:10.1007/s41669-016-0004-1.

2. Kawalec P, Holko P, Paszulewicz A. Cost-utility analysis of Ruconest (conestat alfa) compared to Berinert P (human C1 esterase inhibitor) in the treatment of acute, life-threatening angioedema attacks in patients with hereditary angioedema. Postepy Dermatol Alergol. 2013;30(3):152-8.

3. Hiligsmann M, Reginster JY. Potential cost-effectiveness of denosumab for the treatment of postmenopausal osteoporotic women. Bone. 2010;47(1):34-40.

4. Bertram MY, Lauer JA, De Joncheere K, et al. Cost-effectiveness thresholds: pros and cons. Bull World Health Organ. 2016;94:925-30. 